Original research article

\title{
Chemopreventive action of non-steroidal anti-inflammatory drugs in 9,10-dimethylbenzanthracene induced lung carcinogenesis in BALB/C mice: Expression of COX-1, COX-2 and Nf-кB
}

\author{
Ravi Kishore Saini ${ }^{\mathrm{a}}$, Sankar Nath Sanyal ${ }^{\mathrm{a}}$, Jasvinder Singh Bhatti ${ }^{\mathrm{b}, *}$ \\ a Panjab University, Department of Biophysics, Chandigarh, India \\ ${ }^{\mathrm{b}}$ Sri Guru Gobind Singh College, Department of Biotechnology, Chandigarh, 160019, India
}

\section{A R T I C L E I N F O}

\section{Article history:}

Received 27 December 2017

Accepted 12 March 2018

Available online 20 March 2018

\section{Keywords:}

Non-steroidal anti-inflammatory drugs

COX-1

COX-2

NF- $\mathrm{B}$

Inflammation

Lung cancer

\section{A B S T R A C T}

Non-steroidal anti-inflammatory drugs (NSAIDs) play an effective chemopreventive action against a variety of cancers. The present study aimed at targeting pro-inflammatory cyclooxygenase (COX) and NF-kB mediated inflammatory pathways in 9,10-dimethylbenzanthracene (DMBA) induced lung cancer in BALB/C mice and chemoprotective action of NSAIDs. Animals were divided into five groups and treated with NSAIDs, intratracheally, daily for a period of 18 weeks. Group 1 as control, received vehicle treatment; Group 2 received single dose of DMBA $(10 \mathrm{mg} / \mathrm{kg}$ bw); Group 3, 4 and 5 besides DMBA treatment, also received Aspirin (60 mg/kg bw), Celecoxib $(6.0 \mathrm{mg} / \mathrm{kg}$ bw) and Etoricoxib $(0.6 \mathrm{mg} / \mathrm{kg} \mathrm{bw})$, respectively. DMBA induce DNA damage, apoptosis and expression of COX-1, COX-2 and NF- $\mathrm{B}$ using immunofluorescence and blot analysis were done. The present study demonstrated the formation of micronuclei, over-expression of COX-2 and NF- $\mathrm{B}$ in DMBA induced lung tumorigenesis and thereby suggesting a marked role of inflammation in the tumour progression. Results indicate the formation of micronuclei in DMBA group, which were significantly reduced in aspirin treated group, and totally absent in the celecoxib and etoricoxib groups. In conclusion, co-administration of etoricoxib and celecoxib has significantly reduced the inflammatory potential of the growing neoplasm in DMBA induced lung cancer in male BALB/C mice.

(C) 2018 Faculty of Health and Social Sciences, University of South Bohemia in Ceske Budejovice. Published by Elsevier Sp. z o.o. All rights reserved.

\section{Introduction}

Cancer has become a leading cause of morbidity and mortality with personal, social and economic burden worldwide. WHO estimates reported that there were approx. 14 million new cases in 2012 and this number is predicted to rise by about 70\% over the next 2 decades (Stewart and Wild, 2014). Although the recent advances in early detection and treatment are effectively alleviating the health of cancer patients, however, the no. of people with cancer are still increasing every year (Miller et al., 2016). Urgent preventive and therapeutic measures are required to reduce the burden of cancers and various metabolic diseases, which had emerged as major threat to the humankind.

The chronic inflammation is suggested as the major culprit, involved in the development of cancer (Karin et al., 2002).

\footnotetext{
* Author for correspondence: Sri Guru Gobind Singh College, Department of Biotechnology, Chandigarh 160019, India.

E-mail address: jasvinderbhatti@yahoo.com (J.S. Bhatti).
}

Overexpression of COX2 and/or iNOS has been associated with pathophysiology of certain types of human cancers as well as inflammatory disorders (Karin and Greten, 2005; Surh et al., 2001; Tak and Firestein, 2001). Targeting inflammatory pathways for prevention and therapy of cancer using NSAIDs may be promising. Two different forms of cyclooxygenase enzyme, COX-1 and COX-2 have now been described. COX-1 is constitutively expressed in almost all cells and tissues; its activity appears to depend entirely on the substrate availability. Alternatively, COX-2, acts as an immediate early response gene expressed in response to cytokines, growth factors, carcinogens and other stimuli (Chandrasekharan et al., 2002). It is evident from the earlier studies that elevated expression of COX-2 isoenzyme has been involved in squamous cell carcinoma, non-small cell lung cancer (NSCLC) and certain types of pulmonary cancers (Huang et al., 1998; Petkova et al., 2004; Rishikesh and Sadhana, 2003; Tsujii and DuBois, 1995). Nuclear factor- $\kappa \mathrm{B}(\mathrm{NF}-\kappa \mathrm{B})$, initially discovered as a transcription factor in the nucleus of the $B$ cells that binds to the enhancer of the kappa light chain of immunoglobulin, has since been shown to be 
expressed ubiquitously in the cytoplasm of all types of cells (Colby et al., 1998). NF-кB activation has been associated with the initiation and progression of several human cancers (Lee et al., 2005; Sweeney et al., 2004) and considered a molecular link between chronic inflammation and cancer development (Karin and Greten, 2005; Luo et al., 2005). Several lines of evidences suggest that chronic inflammation may contribute to the process of lung carcinogenesis through activation of a number of molecular pathways, including NF-кB (Ballaz and Mulshine, 2003; Naugler and Karin, 2008; Tak and Firestein, 2001; Tang et al., 2006). In NSCLC cell lines, it has been reported that tobacco components stimulate NF- $\kappa \mathrm{B}$ dependent survival of the cancer cells (Tsurutani et al., 2005) and the COX-2 inhibitor celecoxib suppresses NF-кB p65 nuclear immunolocalization induced by various carcinogens (Shishodia et al., 2004).

Non-steroidal anti-inflammatory drugs (NSAIDs) have considerable potential to act against various types of cancers (Thun et al., 2002). Various epidemiological studies demonstrated the reduced risk of cancer in persons who regularly use aspirin and other NSAIDs (Antonakopoulos and Karamanolis, 2007; Cao et al., 2016; Mercadante, 2005). Previous studies reported the chemoprotective action of various NSAIDs against different types of cancers (Bilani et al., 2017; Ghanghas et al., 2016; Vaish et al., 2013). The main purpose of this study was to investigate the chemopreventive role of NSAIDs (aspirin, celecoxib and etoricoxib) against the 9,10-dimethyl benzanthracene (DMBA) induced lung cancer in $\mathrm{BALB} / \mathrm{C}$ mice. Further we also investigate the possible link of tumour associated macrophage and inflammation.

\section{Materials and methods}

\section{Chemicals}

9,10-Dimethyl benzanthracene (DMBA) and Bradford reagent were purchased from Sigma-Aldrich (St. Louis, MO, USA). Primary antibody against COX-1, COX-2 and NF- $\mathrm{KB}$ (p65) and anti-mouse $\beta$-actin were procured from Santa Cruz Biotechnology Inc., CA(USA). Alkaline phosphatase conjugated secondaryantibodies andBCIP-NBT was obtained from Genei, Bangalore(India).All NSAIDs were obtained from Ranbaxy Research Lab (Gurgaon, India). All other chemicals and reagents used in the present study were of the analytical grade and procured from the reputed Indian manufacturers.

\section{Experimental design}

Male albino mice of BALB/C inbred strain, weighing 25-30 g were procured from the central animal house of Panjab University Chandigarh. All the animals were comfortably housed in clean polypropylene cages and were acclimatized to standard chow diet ad libitum with free access to water under controlled temperature and humidity with a $12 \mathrm{~h}$ light/dark cycle. The animals were taken in each group and tagged for identification marks. The present study was ethically approved by Institutional Ethics Committee on the Use of Experimental Animals of the Panjab University, Chandigarh, India.

All the animals were divided into five different groups with six animals in each group:

1. Control group: Animals were administrated a single intratracheal instillation of vehicle $(0.9 \% \mathrm{NaCl})+0.5 \%$ Carboxymethyl cellulose (CMC) per oral (p.o.) daily.

2. DMBA group: Animals were administrated a single intratracheal dose of DMBA ( $10 \mathrm{mg} / \mathrm{kg}$ bw) in $0.9 \% \mathrm{NaCl}$.

3. DMBA + aspirin group: Animals were administrated a single intra-tracheal dose of DMBA ( $10 \mathrm{mg} / \mathrm{kg}$ bw) in $0.9 \% \mathrm{NaCl}+$ aspirin $(60 \mathrm{mg} / \mathrm{kg}$ bw) dissolved in $0.5 \%$ CMC p.o. daily.
4. DMBA + celecoxib group: Animals were administrated a single intra-tracheal dose of DMBA $(10 \mathrm{mg} / \mathrm{kg}$ bw) in $0.9 \% \mathrm{NaCl}+$ celecoxib $(6 \mathrm{mg} / \mathrm{kg}$ bw) dissolved in $0.5 \%$ CMC p.o. daily.

5. DMBA + etoricoxib group: Animals were administrated a single intra-tracheal dose of DMBA ( $10 \mathrm{mg} / \mathrm{kg}$ bw) in $0.9 \% \mathrm{NaCl}+$ etoricoxib $(0.6 \mathrm{mg} / \mathrm{kg}$ bw) dissolved in $0.5 \%$ CMC p.o. daily.

All the animals were sacrificed after an overnight fast with free access to water. The lung tissue was removed and used for further studies.

\section{Immunohistochemistry}

About $5 \mu \mathrm{m}$ thick paraffin sections of the lung tissues were deparaffinised in three changes of xylene for $15 \mathrm{~min}$. The sections were then gradually hydrated to water. The non-specific staining was blocked by incubating the sections with $2 \% \mathrm{BSA}$ in phosphate buffered saline (PBS $10 \mathrm{mM}, \mathrm{pH} 7.2$ ). The sections were then incubated with the polyclonal antibody against COX-1, COX-2 and NF- $\kappa B$ (p65) (1:1000) in a moist chamber for $2 \mathrm{~h}$ at $37^{\circ} \mathrm{C}$. After incubation, the sections were then incubated with alkaline phosphatase labelled secondary antibody for $2 \mathrm{~h}$, rewashed again as described above and the reaction product developed using BCIPNBT. Reaction was terminated by washing with distilled water after with sections were counterstained with methyl green and, mounted in DPX.

\section{Western immunoblotting}

For preparation of proteins extracts, lungs were removed and rinsed from the different treatment groups after completion of 18 weeks. Total lysate was prepared in fresh ice-cold protein lysis buffer (10 mM TrisNaCl, 5 mM EDTA, 1\% Triton X-100, 1 mM PMSF and $2 \mathrm{mM}$ DTT $\mathrm{pH} 8.0$ ). The extracts were cleared by centrifugation at $10,000 \mathrm{rpm}$ for $10 \mathrm{~min}$ at $40^{\circ} \mathrm{C}$. The supernatants were collected as the total lysate and protein concentration was determined. The cell lysate proteins were separated by SDS-PAGE and stained with Coomassie brilliant blue (CBBR-250) to confirm the migration before performing the Western immunoblot experiments with a highly sensitive method (Wang et al., 2007). The separated proteins were electrophoretically transferred to nitrocellulose membrane (Genei, Bangalore, India). Immunoblot was prepared using primary antibodies (COX-1, COX-2 and NF-кB (p65)-1:1000), and alkaline phosphatase-conjugated secondary antibody at a dilution of $1: 10,000$. BCIP-NBT detection system was used to develop the blots. Bands obtained were densitometrically analysed using Image $\mathrm{J}$ software (free available online) and the density expressed as grey values in the densitometric units.

\section{Isolation of alveolar macrophage}

Alveolar macrophages were isolated by the method of Lavnikova et al. (1993) with slight modifications. In brief, after sacrifice of the animal the chest was opened and the lungs excised. The trachea and major bronchi were removed, cut into small pieces and chopped. The chopped tissues were incubated in ice cold Ca2 +/Mg2 + free Hank's balanced salt solution (HBSS) containing $0.005 \%$ DNAse I (HBSS + DNAse) for 30 min with periodic agitation. After incubation the solution was filtered through a $1.5 \mathrm{~mm}$ filter, washed and subjected to metrizamide gradient centrifugation ( $2400 \mathrm{rpm}, 4^{\circ} \mathrm{C}, 30 \mathrm{~min}$ ) for the elimination of red blood cells, dead cells and the debris. The recovered cells were $98 \%$ viable as determined by trypan blue dye exclusion (Strober, 2001). 


\section{Macrophage viability assay}

Macrophage population viability was assayed using the 3-(4,5dimethylthiazol-2-yl)-2,5-diphenyltetrazolium bromide (MTT) staining as described earlier (Mosmann, 1983). Briefly, $50 \mu \mathrm{l}$ of the pneumocyte suspension was incubated with $20 \mu \mathrm{l}$ of MTT in a humidified atmosphere of 5\% CO2 and $95 \%$ air at $37{ }^{\circ} \mathrm{C}$ for $2-3 \mathrm{~h}$. The purple blue formazan precipitate was dissolved in $100 \mu \mathrm{l}$ of DMSO and optical density recorded at $580 \mathrm{~nm}$ in a STAT Fax 325 + strip type ELISA reader.

\section{Micronucleus test}

Micronucleus assay was performed in the bone marrow according to the previous procedures (Hayashi, 2007). After sacrifice of the animals, the femurs were rapidly removed, cut at the proximal end and flushed with fetal calf serum in order to extract bone marrow cells. Cell suspensions were centrifuged for $10 \mathrm{~min}$ at $1,000 \mathrm{~g}$, the supernatant carefully taken off and the pellet smeared on clean microscope slides. The slides were then air-dried and stained with May-Gruenwald and Giemsa solutions in phosphate buffer ( $\mathrm{pH} 6.8$ ). Approximately $100-200$ polychromatic erythrocytes (PCE) per animal were scored for the presence of micronuclei.

Morphological appraisal of apoptosis in lung associated macrophage

Acridine orange-ethidium bromide co-staining procedure was performed according to the details provided in a previous study (Baker et al., 1994). Briefly, a $10 \mu$ l of cell suspension containing approximately $5 \times 10^{10}$ cells was added to PBS ( $\mathrm{pH} 7.4$ ) containing acridine orange $(1 \mu \mathrm{g} / \mathrm{ml})$ and RNase-A as well as the co-staining with ethidium bromide performed in the same concentration. The cells were then washed and examined under fluorescence microscope $(10 \times)$ (Nikon, Tokyo, Japan) at The National Center for Human Genome Studies and Research, Panjab University, Chandigarh 160014, India. For quantification of apoptotic cells, 100 cells each from four different slides were observed and percentages of apoptotic cells calculated for the individual animal.

\section{Statistical analysis}

For analyzing the data, one-way analysis of variance (ANOVA) was performed using the statistical software package 'SPSS v. 11 for Windows. The post-hoc comparisons of means from different treatment groups were made by the method of least significant difference (LSD). Results corresponding to a p value of 0.05 or less were considered statistically significant.

\section{Results}

\section{DMBA induced DNA damage in bone marrow cells}

Fig. 1 shows the DNA damage reflected by formation of micronuclei in the bone marrow cells of control, DMBA and NSAIDs treated groups. Compared to control group, micronuclei was clearly seen in the DMBA treated group. Although few number of micronuclei were seen in DMBA+aspirin group however no micronuclei was observed in DMBA + celicoxib and DMBA + etoricoxib groups (Table 1 ), suggesting a protective role of celecoxib and etirocoxib against the DNA damage induced by DMBA.

\section{Lung associated macrophage in cancer progression}

Fig. 2A shows the micrograph of macrophages isolated from the lung tumour of DMBA and NSAIDs treated groups. Interestingly, the number of macrophages was much higher in the DMBA group, compared to control or NSAID treated groups. Similarly, compared

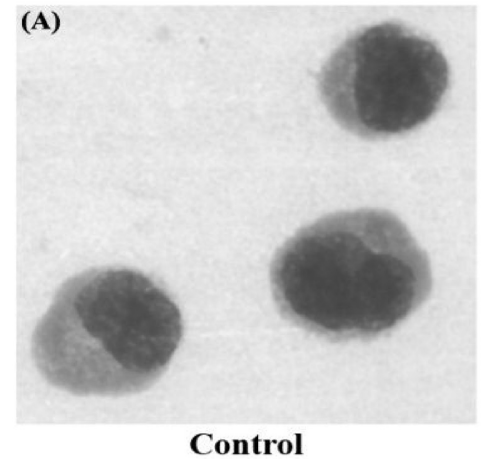

(D)

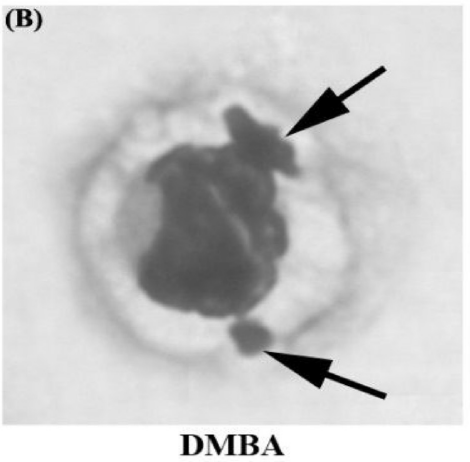

DMBA

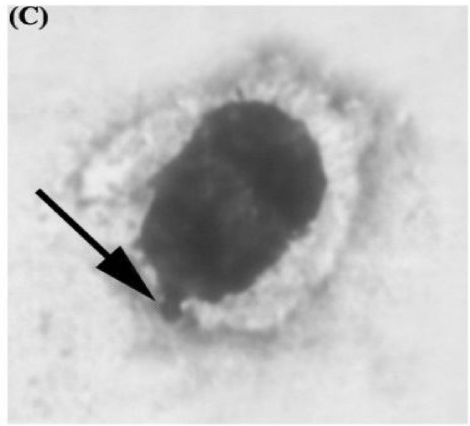

DMBA + Aspirin

(E)

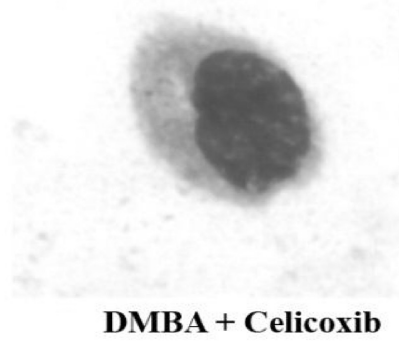

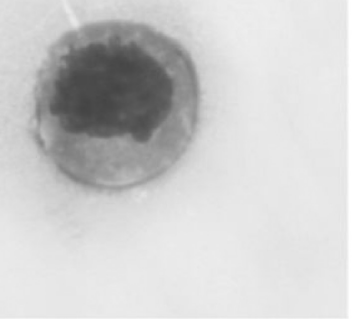

DMBA + Etoricoxib

Fig. 1. (A-E). Genotoxic effect of single intra-tracheal instilled of DMBA and the chemopreventive effect of NSAIDs on mice bone marrow cells. Control (A) shows normal appearance of bone marrow cells. (B) Indicates appearance of micronuclei in DMBA treated group with doses of $10 \mathrm{mg} / \mathrm{kg}$ bw. Plate (C) revealed appearance of small micronuclei in DMBA + aspirin group. Wherever, photomicrograph of (D) and (E) has lack of micronucleus. Resolution $\times 1000$, Wright's staining. Arrow indicates the presence of micronuclei. 
Table 1

Effect of NSAIDs on DMBA induced micronuclei formation in bone marrow cells.

\begin{tabular}{ll}
\hline Treatment & Micronucleus/100cells \\
\hline Control & Nil \\
DMBA & $3.1 \pm 0.01^{* * *}$ \\
DMBA + Aspirin & $1.01 \pm 0.004^{*}$ \\
DMBA + Celicoxib & Nil \\
DMBA + Etoricoxib & Nil \\
\hline
\end{tabular}

Values are mean \pm SD of six independent observations; significantly different from control at ${ }^{*} p<0.05,{ }^{* * *} p<0.001$ by one way ANOVA.

to control group, the macrophages viability was highest in DMBA treated group while quietly high in DMBA + NSAIDs group (Fig. 2C).

NSAIDs induced apoptosis in lung associated macrophage

Fig. 2B shows the apoptosis of macrophages that was evaluated by florescent staining of acridine orange-ethidium bromide in all the study groups. The results indicated few apoptotic macrophages in DMBA group compared to control and DMBA + NSAID treated groups. Fig. 2D shows the percentage of apoptotic lung associated macrophages, where a marked reduction in apoptotic macrophages was observed in the DMBA treated group, compared to the control. However, an increased percentage of apoptotic macrophages were observed in the DMBA + NSAIDs groups as compared to the DMBA alone. The results are more prominent in the DMBA + etoricoxib group as compared to other DMBA + NSAIDs as well as DMBA alone.

Western blot analysis and immunohistochemistry

The expression of COX-1, COX-2, and NF-kB were studied by immunohistochemistry and then further confirmed by Western blot analysis. The expression of the COX-1 protein in the lung tissues was found to be almost the same in Control, DMBA and DMBA + NSAID treated groups as shown in the immunohistochemical analysis (Fig. 3A), which was further supported by the Western

(A)

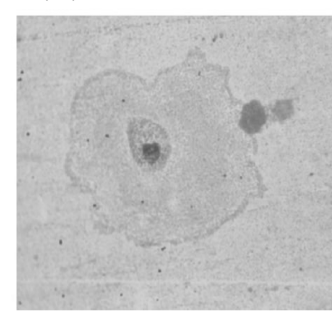

Control

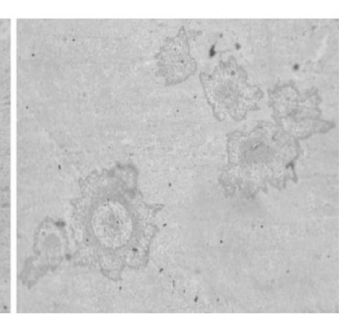

DMBA

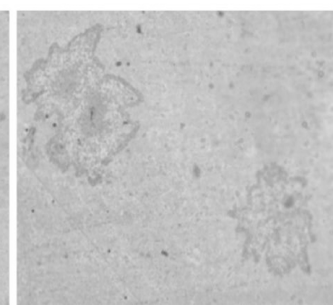

DMBA+Aspirin

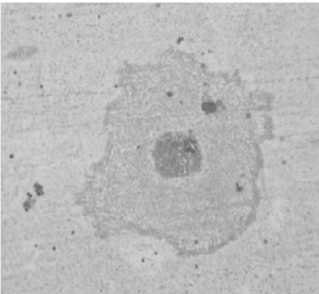

DMBA+Celecoxib

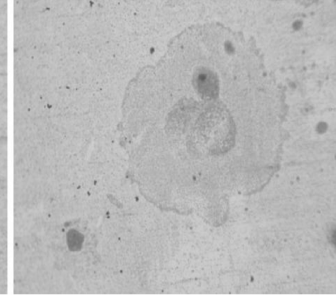

DMBA+Etoricoxib

(B)

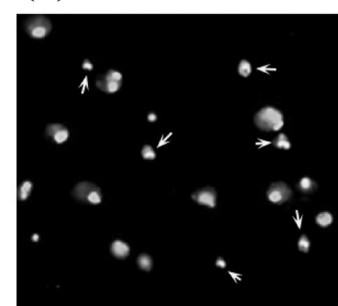

Control

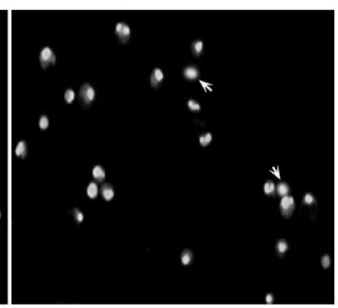

DMBA

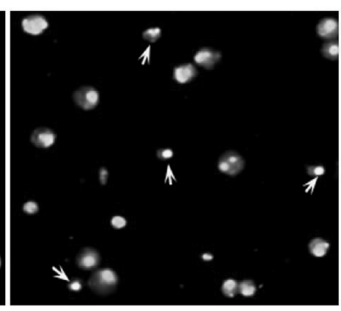

DMBA+Aspirin

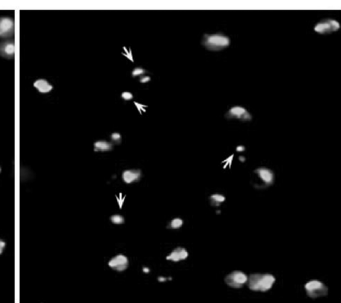

DMBA+Celecoxib

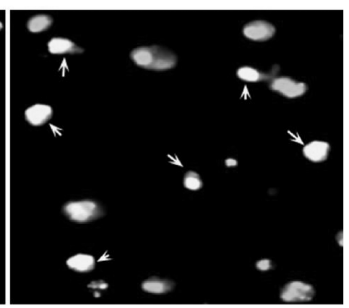

DMBA+Etoricoxib
(C)

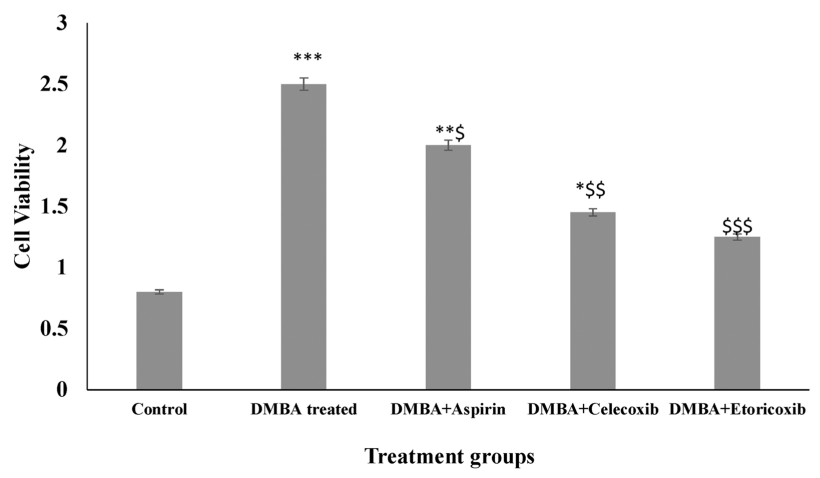

(D)

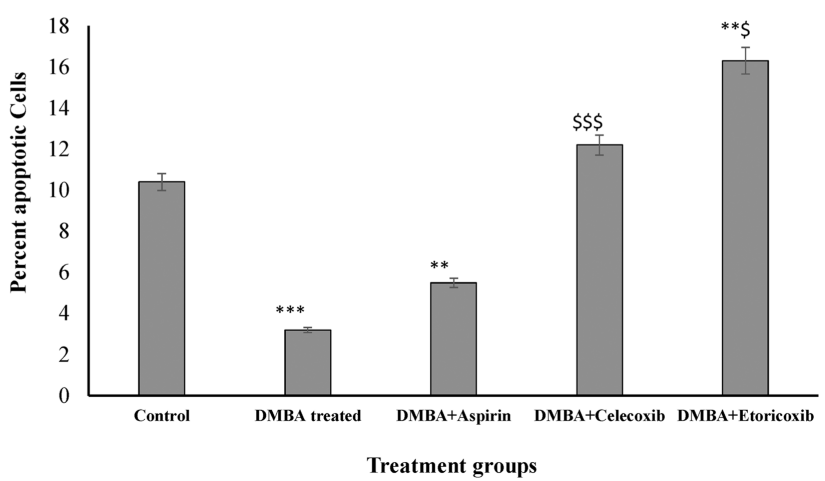

Fig. 2. (A) Micrograph presents the effect of various treatments on the isolated macrophage from the control and different treated animals, resolution $1000 \times$. (B) Shows the apoptosis in lung-associated macrophage by the action of different NSAIDs on DMBA induced carcinogenic effects. (C) The effect of various treatments on the isolated macrophage viability. (D) Histogram shows the percentage of total apoptotic macrophages counted using Fluorescence microscope. Arrow indicates apoptotic cells. The values are mean \pm SD of six animals each. Significantly different from Control at ${ }^{* *} p>0.05,{ }^{* * *} p>0.01,{ }^{* * *} p>0.001$ and DMBA at ${ }^{\$} p>0.05,{ }^{\$ \$} p>0.01$ and ${ }^{\$ \$ \$} p>0.001$ by ANOVA. 

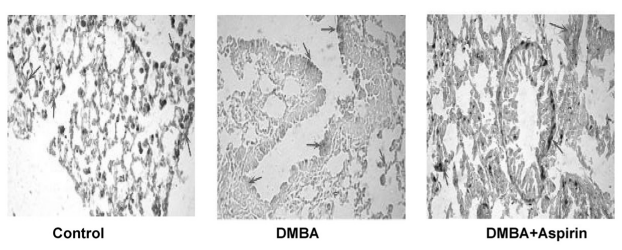

A
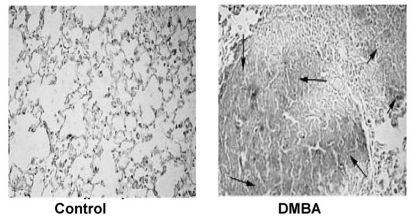

DMBA

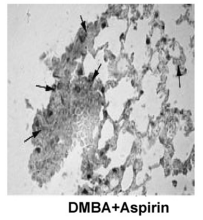

B
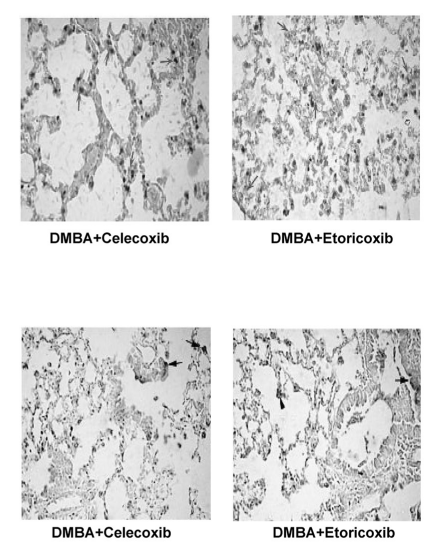

DMBA+Celecoxib
DMBA+Etoricoxib
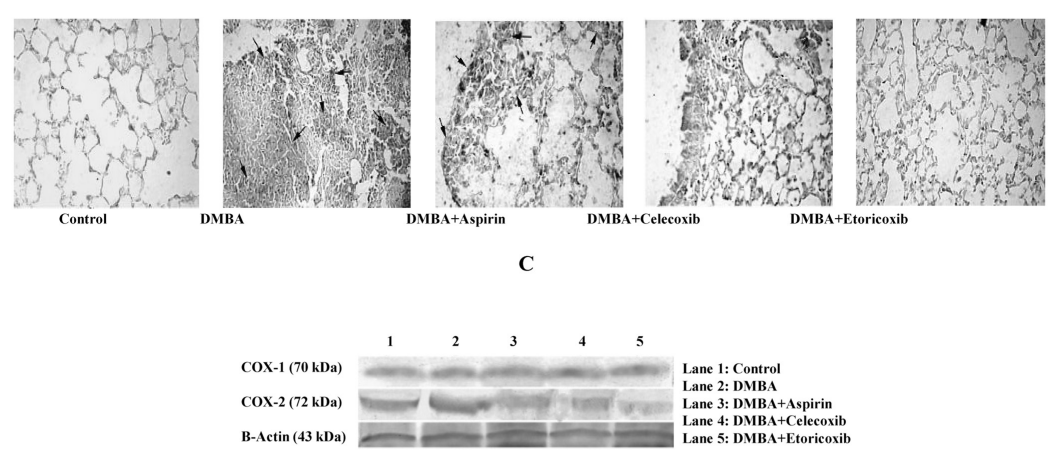

D

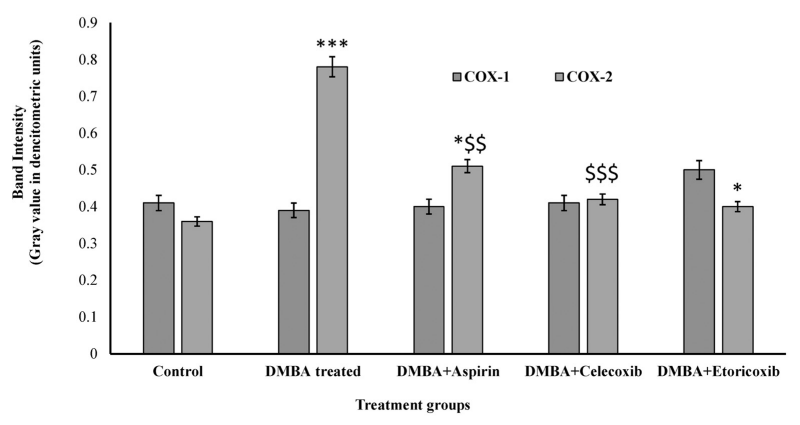

E
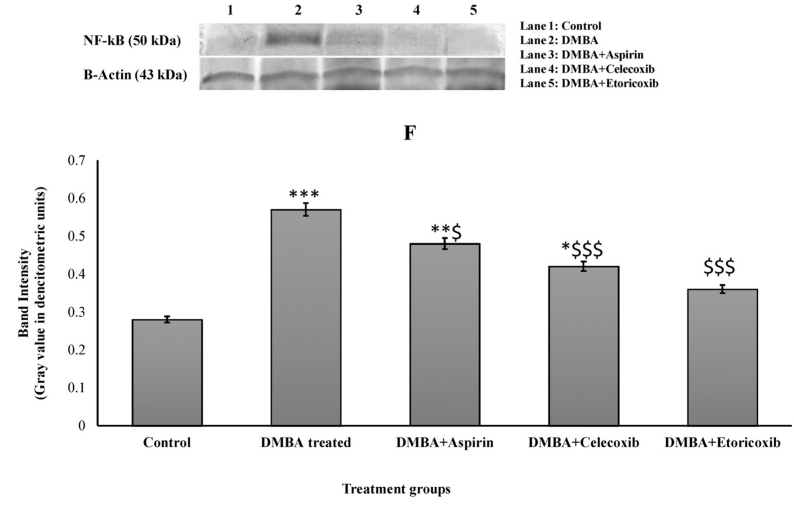

G

Fig. 3. (A-G). Expression of COX-1 (A), COX-2 (B) and NF- $\kappa B(C)$ proteins in respect to NSAIDs treatment against DMBA induced lung carcinogenesis. Arrows indicate the protein expression. D and $\mathrm{F}$ shows the Western blot pattern of COX-1, COX-2 and NF- $\mathrm{B}$ protein, wherever densitometric analysis in E and $\mathrm{G}$ shows the variations in band intensities recorded from the Western blot analysis of COX-1, COX-2 and NF- $\mathrm{B}$ respectively, using image J software for windows, $\beta$-actin used as protein loading control. Significantly different from Control at ${ }^{*} p>0.05,{ }^{* * *} p>0.01,{ }^{* * *} p>0.001$ and DMBA at ${ }^{\$} p>0.05,{ }^{\$ \$} p>0.01$ and ${ }^{\$ \$ \$} p>0.001$ by ANOVA. 
blot analysis (Fig. 3D). Further, no significant differences were observed in the densitometric analysis of COX 1 in all the groups.

The immunohistochemical analysis of the data reveals marked expression of COX-2 in DMBA treated mice, particularly in the tumorous area of lung section, compared to control group. However, the COX-2 expression was normal in NSAIDs treated groups i.e. DMBA + celecoxib and DMBA+etoricoxib group (Fig. 3B). However, expression of COX-2 was seen in the DMBA + aspirin treated group, but to a lesser extent, indicating the less effectiveness of aspirin in inhibiting the COX-2 expression. These results were further confirmed by Western immunoblot and densitometric analysis (Fig. 3D). Also, a marginal increase was observed in COX 2 expression in DMBA+aspirin group when compared with control, indicating aspirin as a non-specific COX inhibitor that failed to lower the COX-2 expression in the lung tissue (Fig. 3E).

The expression of NF- $\mathrm{KB}$ was not observed in controls, but highly expressed in DMBA treated group (Fig. 3C). Although negligible expression was seen in the DMBA+aspirin treated group, however, no expression was seen in lung tissue of the DMBA + celicoxib and a minor expression in the DMBA + etoricoxib group, the reason for which is not clear. NF- $\kappa B$ expression pattern was confirmed in Western immunoblot analysis when compared to control (Fig. 3F). Moreover, the densitometric analysis clearly showed the relative lack of expression of NF- $\kappa B$ in DMBA + celecoxib and DMBA + etoricoxib treated animals (Fig. 3G).

\section{Discussion}

The present study was undertaken to evaluate the chemopreventive response of non-selective (aspirin) and selective (celecoxib and etoricoxib) non-steroidal anti-inflammatory drugs in the lung carcinogenesis induced by DMBA and their correlation with COX-1, COX-2 and NF-kB. While aspirin is the traditional NSAID inhibiting both COX-1 and COX-2 (Lanas et al., 2006), celecoxib is the specific inhibitor for COX-2, sparing the activity of COX- 1 and therefore the generation of the beneficial prostanoids in tissue homeostasis (Cosme et al., 2000). Celecoxib is also the only NSAIDs approved so for by the US FDA for clinical use in familial adenomatous polyposis, a premalignant form of colon cancer (Saini and Sanyal, 2009). Etoricoxib is further developed as much improved second generation COX-2 specific inhibitor (Cryer, 2003).

Micronuclei frequency is a sensitive indicator of genetic/ mutagenic damage (Balakrishnan et al., 2007; Wu et al., 2004). DMBA is a potent genotoxic agent that causes the alteration of normal bone marrow cells when administered into the animals (Sugunadevi et al., 2012) and the effect is retained even after a long period (Balakrishnan et al., 2007). A hallmark of neoplastic transformation is the accumulation of genetic lesions which can be characterized by having increased micronuclei frequency. The degree of frequency is positively correlated with the tumour progression (Cheng and Loeb, 1997). Previous studies have suggested that the presence of one or more micronuclei in peripheral erythrocytes in rodent is an accepted marker of chromosomal breakage or losses that occurred before the extrusion of the nucleus during erythrocytes differentiation (Gaziev et al., 1996; Venkatesh et al., 2007). In the present study, the micronuclei formation can be sufficiently seen even in the group of DMBA+aspirin. The previous study also reported an increase in the micronucleus formation in human fibroblast cell cultures on the addition of aspirin, although aspirin does not appear to play any role in mutagenesis (Meisner and Inhorn, 1972). However, several NSAIDs have shown their ability to reduce micronuclei formation due to their free radical scavenging capability (Aruoma and Halliwell, 1988; Sudheer Kumar et al., 2003). It is hypothesized that NSAIDs may protect against reactive oxygen species (ROS) induced DNA damage by scavenging or quenching various oxygen free radicals. Hydroxamic acid derivatives of various NSAIDs including ibuprofen, fenoprofen, ketoprofen, indomethacin, and diclofenac have been shown to possess significant antioxidant, radical scavenging and metal chelating activities (Koncic et al., 2009).

Chronic inflammation plays an important role in tumour growth, invasion, and metastasis (Coussens and Werb, 2002). This process is meticulously regulated by the local increase of the activity of a variety of angiogenic factors, such as interleukin-8, vascular endothelial growth factor, basic fibroblast growth factor, and transforming growth factor- $\alpha$ (Folkman and Shing, 1992; Olofsson et al., 1996). Substantial evidence suggests that inflammatory cells such as macrophages can interact with cancer cells and express angiogenic factors (Solinas et al., 2009). In the present study, we isolated the macrophages from the lung tissue of DMBA and NSAIDs treated animals. Further, we observed the viability of macrophage and the effect of various NSAIDs on the apoptosis in macrophage population. The interaction of lung cancer cells and macrophages can promote the expression of angiogenic factor IL-8 in cancer cells (White et al., 2001). In addition, other study demonstrated that macrophages also express arachidonate metabolites which are the COX mediated pro-inflammatory molecules (Torisu et al., 2000). NSAIDs are the potent COX inhibitors, both selective and nonselective which may inhibit arachidonate production. Several lines of evidences indicates that NSAIDs use can reduce the risk of colon cancer and may play a preventative role for lung and other cancer (Saini and Sanyal, 2008, 2009, 2012; Saini et al., 2009, 2012a,b; Ulrich et al., 2006).

The expression of COX-1 protein in the lung tissues was found to be almost the same, and these results indicate that COX-1 may not play any significant role in the process of lung tumorigenesis. COX-2 acts as an immediate early response gene expressed in response to cytokines, growth factors, carcinogens and other stimuli. In the initial report describing COX-2 in human lung cancer, a previous study assessed COX-2 expression in NSCLC and normal adjacent lung tissue of resected specimens (Huang et al. 1998). Analysis of COX-2 protein in the lung tissue of different groups revealed low expression of COX-2 protein in the control, while sections from DMBA treated animals show intense cytoplasmic expression of COX-2 in various locations of lung sections. Selective COX-2 inhibitors, celecoxib and etoricoxib reduced the expression of COX-2 protein. These reports, together with the other studies documented an increase in COX-2 expression in precursor lesions (Hosomi et al., 2000; Wolff et al., 1998). A common polymorphism in the COX-2 gene was associated with the increased risk of lung cancer (Campa et al., 2004). Several epidemiological studies indicate a decreased incidence of lung cancer in patients who regularly take NSAIDs particularly the specific COX-2 inhibitors (Olsen et al., 2008; Schreinemachers and Everson, 1994). In supporting the involvement of COX-2 in the pathogenesis of lung cancer, mounting evidence further indicate that tumour COX-2 activity has a multi-faceted role in conferring the malignant and metastatic phenotype of lung cancer.

Constitutively expressed NF- $\kappa$ B is a hallmark of a wide variety of tumours, including breast, colon, prostate, pancreatic, lung, head and neck, skin, etc. (Collins et al., 2000). NF- $\kappa B$ has been implicated in carcinogenesis because it regulates genes critical to the process of cancer including cell survival, cell adhesion, inflammation, differentiation, apoptosis and angiogenesis (Mitsiades et al., 2002). Given the importance of NF- $\kappa \mathrm{B}$ activated pathways in proliferative and anti-apoptotic responses, agents that suppress these pathways are anticipated to be useful in the prevention and treatment of cancer (Huang et al., 1998). It is known that COX-2 gene has been shown to be regulated at the promoter level by NF-кB (Stark et al., 2007). The COX-2 promoter contains two potential NF- $\kappa B$ binding 
sites, and NF- $\kappa \mathrm{B}$ is a positive regulator of COX-2 expression in response to various cytokines and growth factors (Tanabe and Tohnai, 2002). Our study results suggest that DMBA might have induced COX-2 expression and is mediated through the activation of the NF- $\kappa \mathrm{B}$ associated pathways.

\section{Conclusions}

We conclude that the DMBA induce alterations in DNA and promote inflammation while the anti-inflammatory efficacy of COX-2 selective NSAIDs, celecoxib and etoricoxib has the potential to reduce the inflammation. Further, this study also emphasizes the role of NF- $\kappa$ B and COX-2, which are critical molecular targets of chemoprevention and are important players in the process of lung carcinogenesis.

\section{Conflict of interests}

The authors have no conflict of interests to declare in regard to this article.

\section{Acknowledgements}

The present study was supported by the Indian Council of Medical Research in the form of senior research fellowship grant No-3/2/2/III/2007/NCD-III is duly acknowledged.

\section{References}

Antonakopoulos, N., Karamanolis, D.G., 2007. The role of NSAIDs in colon cancer prevention. Hepatogastroenterology 54 (78), 1694-1700.

Aruoma, O.I., Halliwell, B., 1988. The iron-binding and hydroxyl radical scavenging action of anti-inflammatory drugs. Xenobiotica 18 (4), 459-470.

Baker, A.J., Mooney, A., Hughes, J., Lombardi, D., Johnson, R.J., Savill, J., 1994. Mesangial cell apoptosis: the major mechanism for resolution of glomerular hypercellularity in experimental mesangial proliferative nephritis. J. Clin. Invest. 94 (5), 2105-2116.

Balakrishnan, S., Menon, V.P., Manoharan, S., Rajalingam, K., 2007. Antigenotoxic effect of ferulic acid in 7,12-dimethyl benz(a)-anthracene (DMBA) induced genotoxicity. Afr. J. Tradit. Complement. Altern. Med. 5 (1), 32-38.

Ballaz, S., Mulshine, J.L., 2003. The potential contributions of chronic inflammation to lung carcinogenesis. Clin. Lung Cancer 5 (1), 46-62.

Bilani, N., Bahmad, H., Abou-Kheir, W., 2017. Prostate cancer and aspirin use: synopsis of the proposed molecular mechanisms. Front. Pharmacol. 8, 145.

Campa, D., Zienolddiny, S., Maggini, V., Skaug, V., Haugen, A., Canzian, F., 2004 Association of a common polymorphism in the cyclooxygenase 2 gene with risk of non-small cell lung cancer. Carcinogenesis 25 (2), 229-235.

Cao, Y., Nishihara, R., Wu, K., Wang, M., Ogino, S., Willett, W.C., et al., 2016. Population-wide impact of long-term use of aspirin and the risk for cancer. JAMA Oncol. 2 (6), 762-769.

Chandrasekharan, N.V., Dai, H., Roos, K.L., Evanson, N.K., Tomsik, J., Elton, T.S., et al., 2002. COX-3, a cyclooxygenase-1 variant inhibited by acetaminophen and othe analgesic/antipyretic drugs: cloning, structure, and expression. Proc. Natl. Acad. Sci. U. S. A. 99 (21), 13926-13931.

Cheng, K.C., Loeb, L.A., 1997. Genomic stability and instability: a working paradigm. Curr. Top. Microbiol. Immunol. 221, 5-18.

Colby, T.V., Wistuba, I.I., Gazdar, A., 1998. Precursors to pulmonary neoplasia. Adv. Anat. Pathol. 5 (4), 205-215.

Collins, T.S., Lee, L.F., Ting, J.P., 2000. Paclitaxel up-regulates interleukin-8 synthesis in human lung carcinoma through an NF-kappaB- and AP-1-dependent mechanism. Cancer Immunol. Immunother. 49 (2), 78-84.

Cosme, R., Lublin, D., Takafuji, V., Lynch, K., Roche, J.K., 2000. Prostanoids in human colonic mucosa: effects of inflammation on $\mathrm{PGE}(2)$ receptor expression. Hum. Immunol. 61 (7), 684-696.

Coussens, L.M., Werb, Z., 2002. Inflammation and cancer. Nature 420 (6917), 860867.

Cryer, B., 2003. The role of cyclooxygenase selective inhibitors in the gastrointestinal tract. Curr. Gastroenterol. Rep. 5 (6), 453-458.

Folkman, J., Shing, Y., 1992. Angiogenesis. J. Biol. Chem. 267 (16), 10931-10934.

Gaziev, A.I., Sologub, G.R., Fomenko, L.A., Zaichkina, S.I., Kosyakova, N.I., Bradbury, R.J., 1996. Effect of vitamin-antioxidant micronutrients on the frequency of spontaneous and in vitro gamma-ray-induced micronuclei in lymphocytes of donors: the age factor. Carcinogenesis 17 (3), 493-499.

Ghanghas, P., Jain, S., Rana, C., Sanyal, S.N., 2016. Chemoprevention of colon cancer through inhibition of angiogenesis and induction of apoptosis by nonsteroidal anti-inflammatory drugs. J. Environ. Pathol. Toxicol. Oncol. 35 (3), 273-289.
Hayashi, M., 2007. In vivo rodent micronucleus assay. In: Obe, G., Vijayalaxmi (Eds.), Chromosomal Alterations. Springer Verlag, Berlin, pp. 257-270.

Hosomi, Y., Yokose, T., Hirose, Y., Nakajima, R., Nagai, K., Nishiwaki, Y., et al., 2000. Increased cyclooxygenase 2 (COX-2) expression occurs frequently in precursor lesions of human adenocarcinoma of the lung. Lung Cancer 30 (2), 73-81.

Huang, C., Taki, T., Adachi, M., Konishi, T., Higashiyama, M., Miyake, M., 1998. Mutations in exon 7 and 8 of p53 as poor prognostic factors in patients with non-small cell lung cancer. Oncogene 16 (19), 2469-2477.

Karin, M., Greten, F.R., 2005. NF-кB: linking inflammation and immunity to cancer development and progression. Nat. Rev. Immunol. 5 (10), 749-759.

Karin, M., Cao, Y., Greten, F.R., Li, Z.-W., 2002. NF-кB in cancer: from innocent bystander to major culprit. Nat. Rev. Cancer 2 (4), 301-310.

Koncic, M.Z., Rajic, Z., Petric, N., Zorc, B., 2009. Antioxidant activity of NSAID hydroxamic acids. Acta Pharm. 59 (2), 235-242.

Lanas, A., Garcia-Rodriguez, L.A., Arroyo, M.T., Gomollon, F., Feu, F., Gonzalez-Perez, A., et al., 2006. Risk of upper gastrointestinal ulcer bleeding associated with selective cyclo-oxygenase-2 inhibitors, traditional non-aspirin non-steroidal anti-inflammatory drugs, aspirin and combinations. Gut 55 (12), 1731-1738

Lavnikova, N., Prokhorova, S., Helyar, L., Laskin, D.L., 1993. Isolation and partial characterization of subpopulations of alveolar macrophages, granulocytes, and highly enriched interstitial macrophages from rat lung. Am. J. Respir. Cell Mol. Biol. 8 (4), 384-392.

Lee, S.H., Seo, M.J., Choi, S.M., Sohn, Y.S., Kang, K.K., Ahn, B.O., et al., 2005. DA-9201 shows anti-asthmatic effects by suppressing NF-kappaB expression in an ovalbumin-induced mouse model of asthma. Arch. Pharm. Res. 28 (12), 13501357.

Luo, J.L., Kamata, H., Karin, M., 2005. The anti-death machinery in IKK/NF-kappaB signalling. J. Clin. Immunol. 25 (6), 541-550.

Meisner, L.F., Inhorn, S.L., 1972. Chemically-induced chromosome changes in human cells in vitro. Acta Cytol. 16 (1), 41-47.

Mercadante, S., 2005. Looking for the role of NSAIDs in cancer pain. J. Clin. Oncol. 23 (10), 2442-2443.

Miller, K.D., Siegel, R.L., Lin, C.C., Mariotto, A.B., Kramer, J.L., Rowland, J.H., et al., 2016. Cancer treatment and survivorship statistics. CA Cancer J. Clin. 66 (4), 271-289.

Mitsiades, N., Mitsiades, C.S., Poulaki, V., Chauhan, D., Richardson, P.G., Hideshima, T., et al., 2002. Biologic sequelae of nuclear factor-kappaB blockade in multiple myeloma: therapeutic applications. Blood 99 (11), 4079-4086.

Mosmann, T., 1983. Rapid colorimetric assay for cellular growth and survival: application to proliferation and cytotoxicity assays. J. Immunol. Methods 65 (1-2), 55-63.

Naugler, W.E., Karin, M., 2008. NF- $\kappa$ B and cancer - identifying targets and mechanisms. Curr. Opin. Genet. Dev. 18 (1), 19-26.

Olofsson, B., Pajusola, K., von Euler, G., Chilov, D., Alitalo, K., Eriksson, U., 1996 Genomic organization of the mouse and human genes for vascular endothelial growth factor B (VEGF-B) and characterization of a second splice isoform. J. Biol. Chem. 271 (32), 19310-19317.

Olsen, J.H., Friis, S., Poulsen, A.H., Fryzek, J., Harving, H., Tjonneland, A., et al., 2008. Use of NSAIDs, smoking and lung cancer risk. Br. J. Cancer 98 (1), 232-237.

Petkova, D.K., Clelland, C., Ronan, J., Pang, L., Coulson, J.M., Lewis, S., et al., 2004 Overexpression of cyclooxygenase-2 in non-small cell lung cancer. Respir. Med. 98 (2), 164-172.

Rishikesh, M.K., Sadhana, S.S., 2003. Prostaglandins and cyclooxygenase: their probable roles in cancer. Indian J. Pharmacol. 35 (1), 3-12.

Saini, R.K., Sanyal, S.N., 2008. Pulmonary carcinogenesis in mice with a single intratracheal instillation of 9, 10-dimethyl benz[a]anthracene. Drug Chem. Toxicol. 31 (4), 459-471.

Saini, R.K., Sanyal, S.N., 2009. Chemopreventive effect of nonsteroidal antiinflammatory drugs on 9, 10-dimethylbenz[a]anthracene-induced lung carcinogenesis in mice. Oncol. Res. 17 (11-12), 505-518.

Saini, M.K., Sanyal, S.N., 2012. PTEN regulates apoptotic cell death through PI3-K/ Akt/GSK3beta signalling pathway in DMH induced early colon carcinogenesis in rat. Exp. Mol. Pathol. 93 (1), 135-146.

Saini, M.K., Sharma, P., Kaur, J., Sanyal, S.N., 2009. The cyclooxygenase-2 inhibitor etoricoxib is a potent chemopreventive agent of colon carcinogenesis in the rat model. J. Environ. Pathol. Toxicol. Oncol. 28 (1), 39-46.

Saini, M.K., Sanyal, S.N., Vaiphei, K., 2012a. Piroxicam and C-phycocyanin mediated apoptosis in 1,2-dimethylhydrazine dihydrochloride induced colon carcinogenesis: exploring the mitochondrial pathway. Nutr. Cancer 64 (3), 409418.

Saini, M.K., Vaiphei, K., Sanyal, S.N., 2012b. Chemoprevention of DMH-induced rat colon carcinoma initiation by combination administration of piroxicam and C-phycocyanin. Mol. Cell. Biochem. 361 (1-2), 217-228.

Schreinemachers, D.M., Everson, R.B., 1994. Aspirin use and lung, colon, and breast cancer incidence in a prospective study. Epidemiology 5 (2), 138-146.

Shishodia, S., Koul, D., Aggarwal, B.B., 2004. Cyclooxygenase (COX)-2 inhibitor celecoxib abrogates TNF-induced NF-kappa B activation through inhibition of activation of I kappa B alpha kinase and Akt in human non-small cell lung carcinoma: correlation with suppression of COX-2 synthesis. J. Immunol. 173 (3), 2011-2022.

Solinas, G., Germano, G., Mantovani, A., Allavena, P., 2009. Tumour-associated macrophages (TAM) as major players of the cancer-related inflammation. J. Leukoc. Biol. 86 (5), 1065-1073.

Stark, L.A., Reid, K., Sansom, O.J., Din, F.V., Guichard, S., Mayer, I., et al., 2007. Aspirin activates the NF-kappaB signalling pathway and induces apoptosis in intestinal 
neoplasia in two in vivo models of human colorectal cancer. Carcinogenesis 28 (5), 968-976

Stewart, B.W., Wild, P. (Eds.), 2014. World Cancer Report 2014. IARC, Copenhagen Strober, W., 2001. Trypan blue exclusion test of cell viability. Curr. Protoc. Immunol. 21 (3B) doi:http://dx.doi.org/10.1002/0471142735.ima03bs21 A.3B.1-A.3B.2 Appendix CB.

Sudheer Kumar, M., Unnikrishnan, M.K., Uma Devi, P., 2003. Effect of 5-aminosalicylic acid on radiation-induced micronuclei in mouse bone marrow. Mutat. Res. 527(12), 7-14.

Sugunadevi, G., Suresh, K., Vijayaanand, M.A., Rajalingam, K., Sathiyapriya, J., 2012. Anti-genotoxic effect of Mosinone-A on 7, 12-dimethyl benz[a] anthracene induced genotoxicity in male golden Syrian hamsters. Pathol. Oncol. Res. 18 (1), 69-77.

Surh, Y.J., Chun, K.S., Cha, H.H., Han, S.S., Keum, Y.S., Park, K.K., et al., 2001. Molecular mechanisms underlying chemopreventive activities of anti-inflammatory phytochemicals: down-regulation of COX-2 and iNOS through suppression of NF-kappa B activation. Mutat. Res. 480-481, 243-268.

Sweeney, C., Li, L., Shanmugam, R., Bhat-Nakshatri, P., Jayaprakasan, V., Baldridge, L.A., et al., 2004. Nuclear factor-kappaB is constitutively activated in prostate cancer in vitro and is overexpressed in prostatic intraepithelial neoplasia and adenocarcinoma of the prostate. Clin. Cancer Res. 10 (16), 5501-5517.

Tak, P.P., Firestein, G.S., 2001. NF-кB: a key role in inflammatory diseases. J. Clin. Invest. 107 (1), 7-11.

Tanabe, T., Tohnai, N., 2002. Cyclooxygenase isozymes and their gene structures and expression. Prostaglandins Other Lipid Mediat. 68-69, 95-114.

Tang, X., Liu, D., Shishodia, S., Ozburn, N., Behrens, C., Lee, J.J., et al., 2006. Nuclear factor- $\kappa \mathrm{B}(\mathrm{nf}-\kappa \mathrm{B})$ is frequently expressed in lung cancer and preneoplastic lesions. Cancer 107 (11), 2637-2646.

Thun, M.J., Henley, S.J., Patrono, C., 2002. Nonsteroidal anti-inflammatory drugs as anticancer agents: mechanistic, pharmacologic, and clinical issues. J. Natl. Cancer Inst. 94 (4), 252-266.

Torisu, H., Ono, M., Kiryu, H., Furue, M., Ohmoto, Y., Nakayama, J., et al., 2000. Macrophage infiltration correlates with tumour stage and angiogenesis in human malignant melanoma: possible involvement of TNFalpha and IL-1alpha. Int. J. Cancer 85 (2), 182-188.

Tsujii, M., DuBois, R.N., 1995. Alterations in cellular adhesion and apoptosis in epithelial cells overexpressing prostaglandin endoperoxide synthase 2. Cell 83 (3), 493-501.

Tsurutani, J., Castillo, S.S., Brognard, J., Granville, C.A., Zhang, C., Gills, J.J., et al., 2005 Tobacco components stimulate Akt-dependent proliferation and NFkappaBdependent survival in lung cancer cells. Carcinogenesis 26 (7), 1182-1195.

Ulrich, C.M., Bigler, J., Potter, J.D., 2006. Non-steroidal anti-inflammatory drugs for cancer prevention: promise, perils and pharmacogenetics. Nat. Rev. Cancer 6 (2), 130-140.

Vaish, V., Piplani, H., Rana, C., Vaiphei, K., Sanyal, S.N., 2013. NSAIDs may regulate EGR-1-mediated induction of reactive oxygen species and non-steroidal antiinflammatory drug-induced gene (NAG)-1 to initiate intrinsic pathway of apoptosis for the chemoprevention of colorectal cancer. Mol. Cell. Biochem. 378 (1-2), 47-64.

Venkatesh, P., Shantala, B., Jagetia, G.C., Rao, K.K., Baliga, M.S., 2007. Modulation o doxorubicin-induced genotoxicity by Aegle marmelos in mouse bone marrow: a micronucleus study. Integr. Cancer Ther. 6 (1), 42-53.

Wang, X., Li, X., Li, Y., 2007. A modified Coomassie Brilliant Blue staining method at nanogram sensitivity compatible with proteomic analysis. Biotechnol. Lett. 29 (10), 1599-1603.

White, E.S, Livant, D.L, Markwart, S, Arenberg D.A., 2001. Monocyte-fibronectin interactions, via alpha(5)beta(1) integrin, induce expression of CXC chemokinedependent angiogenic activity. J. Immunol. 167 (9), 5362-5366.

Wolff, H., Saukkonen, K., Anttila, S., Karjalainen, A., Vainio, H., Ristimaki, A., 1998 Expression of cyclooxygenase-2 in human lung carcinoma. Cancer Res. 58 (22) 4997-5001.

Wu, P.A., Loh, C.H., Hsieh, L.L., Liu, T.Y., Chen, C.J., Liou, S.H., 2004. Clastogenic effect for cigarette smoking but not areca quid chewing as measured by micronuclei in exfoliated buccal mucosal cells. Mutat. Res. 562 (1-2), 27-38. 